\title{
Value of CT-guided percutaneous needle biopsy of bone in the diagnosis of lymphomas based on PET/CT results
}

\author{
Zhiwei Wang, Haifeng Shi, Xiaobo Zhang, Jie Pan and Zhengyu Jin * (D)
}

\begin{abstract}
Background: To evaluate the value of CT-guided percutaneous needle biopsy of bone in the diagnosis of lymphomas based on PET/CT results.

Methods: A retrospective analysis of the records of all patients with percutaneous bone biopsies based on PET/CT results and a final diagnosis of lymphoma between January 2012 and August 2017 was performed. Thirty-one patients were included in this study. The success and complication rates were assessed.

Results: The mean age of the 31 patients was $46.6 \pm 21.2$ years, and there were 16 men and 15 women. A definite diagnosis and accurate histological subtype were obtained in 26 patients, for a success rate of $84 \%$. The most common subtype was diffuse large B cell lymphoma $(n=18)$. The remaining subtypes included three cases of marginal-zone lymphoma, two cases of follicular lymphoma, one case of Hodgkin's lymphoma, one case of peripheral T cell lymphoma, and one case of B cell lymphoblastic lymphoma. No serious complications occurred in any of the patients.

Conclusions: $C T$-guided needle biopsy based on PET/CT results is a reliable means of diagnosing and classifying lymphomas.
\end{abstract}

Keywords: Needle biopsy, Bone, Lymphoma, PET/CT

\section{Background}

Lymphoma commonly occurs in the lymph nodes. However, every category of lymphoma can involve the skeletal system, with bone involvement observed in 16-20\% of patients [1]. Pathological examination is fundamental to the accurate diagnosis of lymphomas, as the symptoms and imaging signs of lymphomas are highly heterogeneous [2-5]. Surgical biopsy is considered the standard for obtaining tissue for diagnosis. However, CT-guided percutaneous needle biopsy has become an important diagnostic tool due to its less invasive nature, shorter recovery time, and lower complication rate [6-10]. In recent years, a shift from open biopsy to CT-guided needle biopsy has occurred in the diagnosis and classification of malignant lymphomas [11-16].

Although CT-guided percutaneous needle biopsy has become the first step for acquiring tissue for the diagnosis

\footnotetext{
* Correspondence: pumchjinzhengyu@sina.com

Department of Radiology, Peking Union Medical College Hospital, Beijing 100730, China
}

of bone lesions [10, 17-24], this technique has been shown to be less efficient in diagnosing lymphoma of bone than other neoplasms and has not been widely used. 2Deoxy-2-[18F] fluorodeoxyglucose positron emission tomography/computed tomography (FDG PET/CT) is increasingly used in cases of lymphoma and performs favourably in bone lesion detection compared to other imaging modalities [25-27]. We believe that CT-guided percutaneous needle biopsy of bone based on PET/CT results may improve the rate of lymphoma diagnosis. The aim of the study was to verify this hypothesis and to discuss the role and indications of this technique.

\section{Methods}

Institutional review board approval was obtained for this retrospective study. A retrospective analysis of the records of all patients with percutaneous bone biopsies based on PET/CT results and a final diagnosis of lymphoma between January 2012 and August 2017 was performed. A total of 31 patients were identified. All

(c) The Author(s). 2019 Open Access This article is distributed under the terms of the Creative Commons Attribution 4.0 International License (http://creativecommons.org/licenses/by/4.0/), which permits unrestricted use, distribution, and 
patients with undiagnosed bone lesions were initially referred to our radiology department for CT-guided needle biopsy. All patients underwent a PET/CT examination for a systematic assessment within 2 weeks before biopsy.

\section{$\mathrm{PET} / \mathrm{CT}$ procedure}

Patients were instructed to fast for $>4 \mathrm{~h}$ before the PET/ CT examination. Images of the whole body were acquired $40-60 \mathrm{~min}$ after 18F-FDG $(0.15 \mathrm{mCi} / \mathrm{kg})$ was injected. The PET/CT datasets were reconstructed automatically, and attenuation correction was performed with CT attenuation. The results were measured using the software on the PET/CT system workstation (TrueD, Siemens Medical Systems).

\section{Biopsies}

Before the biopsy, informed consent was obtained from all patients. All biopsies were performed under CT guidance. Patients were positioned in a prone or supine position depending on the bone lesion location. Patients underwent a CT scan of the area of the hypermetabolic bone lesions of interest based on the PET/CT results (Fig. 1a) using a spiral CT system (Sensation 16, Siemens, Germany or NeuViz 128, Neusoft, China). CT images were obtained at a slice thickness of $5 \mathrm{~mm}$. The entry site was prepared and draped in a sterile fashion.
All biopsies were performed under local anaesthesia consisting of an injection of $5-10 \mathrm{~mL}$ of $1 \%$ lidocaine hydrochloride. All biopsies were performed using a 13G bone biopsy needle (COOK, USA). The biopsy needle was inserted into the lesion. 5 millimetre sections were then obtained to verify the location of the needle tip (Fig. 1b). After the biopsy procedure, CT was immediately performed at the level of the biopsy site to search for the presence of complications, such as bleeding. Biopsy specimens were fixed routinely in 10\% buffered formalin.

\section{Histological analysis}

The lymphoma diagnosis was established by examining haematoxylin and eosin (HE)-stained biopsy sections and performing immunohistochemical staining, including for CD3, CD5, CD8, CD10, CD19, CD20, CD23, CD30, CD43, CD45, CD68, CD79a, AE1/AE3, Ki-67, epithelial membrane antigen (EMA), anaplastic lymphoma kinase (ALK), Cyclin D1, Bcl2, and Bcl6 (Fig. 1c). The diagnosis was reached by the consensus of at least two pathologists. The histological diagnosis was established according to the World Health Organization (WHO) classification of malignant lymphomas [28].

A biopsy was considered successful if a definite diagnosis and accurate malignant lymphoma classification could be established.
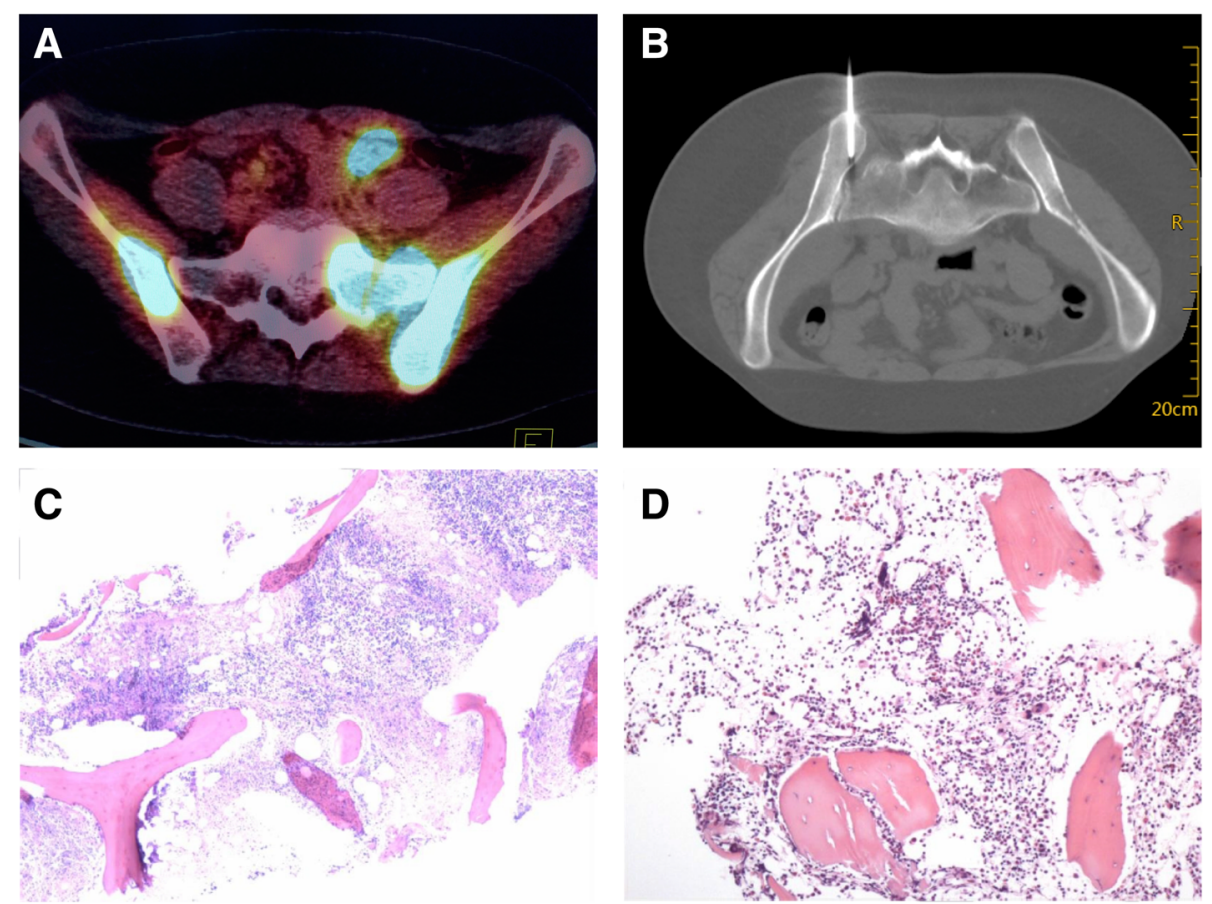

Fig. 1 a PET/CT showed a hypermetabolic lesion in the left ilium of a 26-year-old woman. b Scan during biopsy of the left ilium showed the needle tip in the lesion. c Needle biopsy specimens (with H\&E staining) showed lymphocytic infiltration, confirming the diagnosis of DBLB with immunohistochemical staining. $\mathbf{d}$ This patient also underwent blind needle biopsy of the left iliac crest (for a non-hypermetabolic lesion) in the department of haematology, and the specimen showed normal bone marrow 


\section{Statistical analyses}

Statistical analyses were performed using statistical software (SPSS, version 13.0, Chicago, IL, USA). To calculate $P$-values, Fisher's exact $t$ test was used. All $P$ values of 0.05 and below were considered statistically significant.

\section{Results}

The group of 31 patients included 16 men and 15 women, with a mean age of $46.6 \pm 21.2$ years (range, 16 to 85 years). Tissue samples of the metabolically active sites were obtained from all 31 patients for histological examination and immunohistochemical tests. The biopsy sites are shown in Table 1. Bony destruction was found at 19 biopsy sites on CT examination. The maximum SUV of the biopsy lesions was $8.6 \pm 7.7$.

The characteristics of the lesions we chose for biopsy are listed in Table 1. During each CT-guided core-needle biopsy, two to three specimens were obtained for satisfactory sampling (the total length of the samples obtained was $20-30 \mathrm{~mm}$ ). There were 2 minor complications of haemorrhage. No serious complications were noted in any of the patients who underwent CT-guided needle biopsy.

A definite diagnosis and accurate histological subtyping were achieved by CT-guided needle biopsy in 26 out of 31 patients, for a success rate of $84 \%$. The most common subtype was diffuse large B cell non-Hodgkin's lymphoma (NHL) $(n=18)$. The remaining subtypes included three cases of marginal-zone lymphoma, two cases of follicular lymphoma, one case of Hodgkin's lymphoma (HL), one case of peripheral $\mathrm{T}$ cell lymphoma, and one case of B cell lymphoblastic lymphoma.

Five patients with non-diagnostic needle biopsies were finally diagnosed by the surgical biopsy of other lesions. The final diagnosis in these cases is also listed in Table 1.

Six patients underwent blind needle biopsy of the iliac crest for non-hypermetabolic lesions in the department of haematology, and the specimens showed normal bone marrow (Fig. 1d).

We divided our patients into two groups based on the lesion characteristics of the biopsy site according to the CT examinations: the lesions in group 1 had bone destruction; the lesions in group 2 did not have bone destruction. The success rate of core-needle biopsy was $84 \%(16 / 19)$ in group 1 and 83\% (10/12) in group 2, with no significant difference $(P=1.000)$.

\section{Discussion}

Our retrospective study demonstrates the high accuracy of CT-guided needle biopsy in the diagnosis of lymphoma based on PET/CT results. Bone involvement in lymphoma is common and clinically relevant, as it has prognostic implications. Bone biopsy has its own advantages in lymphoma. The detection of lymphomatous
Table 1 Clinical characteristic of the patients and bone lesions

\begin{tabular}{|c|c|}
\hline Characteristics & Summary $(n=31)$ \\
\hline $\mathrm{Age}^{*}, \mathrm{Y}$ (range) & $46.6(16-85)$ \\
\hline \multicolumn{2}{|l|}{ Gender, n (\%) } \\
\hline Male & $16(51.6)$ \\
\hline Female & $15(48.4)$ \\
\hline \multicolumn{2}{|l|}{ Bone destruction, n (\%) } \\
\hline Yes & $19(61.3)$ \\
\hline No & $12(38.7)$ \\
\hline \multicolumn{2}{|l|}{ Bone marrow biopsy sites, n (\%) } \\
\hline Right humerus & $1(3.2)$ \\
\hline Sternal handle & $1(3.2)$ \\
\hline T3 vertebral body & $1(3.2)$ \\
\hline T8 vertebral body & $2(6.5)$ \\
\hline T11 vertebral body & $1(3.2)$ \\
\hline T12 vertebral body & $1(3.2)$ \\
\hline L2 vertebral body & $1(3.2)$ \\
\hline L3 vertebral body & $2(6.5)$ \\
\hline L4 vertebral body & $1(3.2)$ \\
\hline S1 vertebral body & $1(3.2)$ \\
\hline Left sacrum & $1(3.2)$ \\
\hline Right sacrum & $1(3.2)$ \\
\hline Left ilium & $8(25.8)$ \\
\hline Right ilium & $5(16.1)$ \\
\hline Left femur & $2(6.5)$ \\
\hline Right femur & $1(3.2)$ \\
\hline Right tibia & $1(3.2)$ \\
\hline \multicolumn{2}{|l|}{ Pathology results, n (\%) } \\
\hline Needle biopsy results & $26(83.9)$ \\
\hline Diffuse large B-cell lymphoma & $18(58.1)$ \\
\hline Marginal zone lymphoma & $3(9.7)$ \\
\hline Follicular lymphoma & $2(6.5)$ \\
\hline Hodgkin lymphoma & $1(3.2)$ \\
\hline Peripheral T-cell lymphoma & $1(3.2)$ \\
\hline B cell lymphoblastic lymphoma & $1(3.2)$ \\
\hline Surgical biopsy results & $5(16.1)$ \\
\hline Marginal zone lymphoma & $1(3.2)$ \\
\hline Diffuse large B-cell lymphoma & $1(3.2)$ \\
\hline Peripheral T-cell lymphoma & $2(6.5)$ \\
\hline Hodgkin lymphoma & $1(3.2)$ \\
\hline
\end{tabular}

cells in bone not only may aid in the diagnosis of lymphoma but can also be used as a staging tool in lymphoma, in which bone involvement indicates the highest disease stage [28].

In the past, surgical biopsy was considered the reference standard for obtaining tissue for the diagnosis of 
bone lesions. In recent years, image-guided percutaneous needle biopsy has become the first-line method for acquiring tissue for the diagnosis of bone lesions as a result of its less invasive nature, shorter recovery time, and lower complication rate [17-20]. However, the accuracy of image-guided bone biopsy is generally thought to be lower than that of soft tissue biopsy [18, 20]. Yang et al. evaluated 508 image-guided biopsies and found that bone lesions were more likely to have a non-diagnostic biopsy result than soft tissue lesions and were more likely to require a repeat biopsy [18]. Didolkar et al. evaluated 778 image-guided biopsies and found that bone biopsies had a higher non-diagnostic rate than soft tissue biopsies [20].

Furthermore, lymphoma is also considered the most likely condition to result in a non-diagnostic bone biopsy. Chang et al. retrospectively reviewed 963 consecutive CT-guided musculoskeletal biopsies and found that the diagnostic bone biopsy rate was significantly lower for lymphoma than metastases [22]. However, the CT-guided needle biopsy of soft tissue is a useful and reliable tool in the diagnosis and classification of malignant lymphoma. Balestreri $\mathrm{L}$ et al. retrospectively analysed 145 CT-guided needle biopsies of thoracic and abdominal soft tissue in 137 patients and found that a diagnosis was achieved in 96\% patients with NHL [15]. Wang et al. retrospectively evaluated CT-guided coreneedle biopsy in the diagnosis of primary pulmonary lymphoma and its subtypes and found that the success rate of achieving a definite diagnosis and accurate histological subtyping was $84 \%$ [11].

In our study, a definite diagnosis and accurate histological subtyping were achieved by CT-guided needle biopsy in 26 out of 31 patients, for a success rate of $84 \%$. We consider the relatively high diagnostic rate to be due to two causes. First, we used PET/CT as a reference during biopsy. Guo et al. reported that PET/CT-guided percutaneous biopsy was an effective and safe method that yielded a high diagnostic success rate in the evaluation of hypermetabolic bone lesions in patients with suspected advanced lung cancer [29]. However, biopsy directly guided by PET/CT is still applied sporadically in clinical practice due to the high radiation dose, high cost and complex procedure. The main alternative to PET/ CT guidance is CT-guided biopsy based on PET/CT results. Bitencourt et al. demonstrated that performing CT-guided biopsy based on PET/CT results was reliable, safe, and very accurate diagnostic method [30]. In this study, $95 \%$ of the biopsy procedures yielded conclusive results. PET/CT has become the standard method for assessing lymphoma and has improved the accuracy of staging $[25,26]$. A meta-analysis of seven studies demonstrated a high specificity of PET/CT for the detection of bone involvement in diffuse large B cell lymphoma
[31]. Our diagnostic rate was high for diffuse large B cell lymphoma based on PET/CT results.

Second, we used a relatively large (13G) bone biopsy system. This system is rapid, safe, and highly efficient for sampling and has been used as the most common tool for percutaneous CT-guided bone biopsy in our hospital. Guided by CT, a biopsy specimen approximately $2-3 \mathrm{~cm}$ in length is sufficient for immunohistochemical staining and complete subtyping. Some authors used 14-16G coaxial automated biopsy systems to perform bone biopsy [22]. The coaxial technique is useful for obtaining multiple biopsies in a single session. However, bone is a hard tissue, so it is difficult to adjust the angle of the external cannula for repeat biopsy, and the repeat biopsy specimen is not satisfactory in our experience.

$\mathrm{Li}$ et al. found that lytic bone lesions have a higher diagnostic yield by needle biopsy [21]. When we divided our patients into two groups according to the lesion characteristics, we found that the success rate of biopsy was not significantly different between the two groups. Therefore, the lesion characteristics do not seem to influence the success rate.

Limitations of this study include its retrospective nature and fairly small sample size of 31 patients, which limit the generalizability of our findings. This study did not include all subtypes of lymphoma. In certain disease subtypes, for example, diffuse large B cell lymphoma, the diagnostic yield of needle biopsy was high because the distribution of lymphomatous cells was fairly uniform. Therefore, the typical features of pathological lymphatic tissues are very important for the diagnosis of lymphoma. Five biopsies, in which lymphomatous cells were sparse or unevenly distributed, did not allow a definitive diagnosis to be reached and were considered unsuccessful.

\section{Conclusions}

This study specifically assessed the usefulness of CTguided percutaneous needle biopsy of bone in the diagnosis of lymphomas based on PET/CT results and demonstrates that percutaneous needle biopsy is a safe and accurate technique for providing a tissue diagnosis with a high yield.

\section{Abbreviations}

ALK: Anaplastic lymphoma kinase; EMA: Epithelial membrane antigen; FDG PET/CT: 2-Deoxy-2-[18F] fluorodeoxyglucose positron emission tomography/ computed tomography; HE: Haematoxylin and eosin; WHO: World Health Organization

Acknowledgements

We thank Huanwen Wu for histopathological support.

Ethical approval and consent to participate

This retrospective study was approved by our institutional review board, and the requirement for patient informed consent was waived. 


\section{Authors' contributions}

ZWW and ZYJ designed this study. HFS, XBZ, and JP collected data. ZWW and ZYJ edited and analysed the results. ZWW wrote this manuscript. ZYJ revised the manuscript. All authors read and approved the final manuscript.

\section{Funding}

This study was supported by a grant from the National Natural Science Foundation of China (No. 81401496).

\section{Availability of data and materials}

The datasets analysed in the current study are available from the corresponding author on reasonable request.

\section{Consent for publication}

All authors consent to publish this research.

\section{Competing interests}

The authors declare that they have no conflicts of interest.

Received: 13 December 2018 Accepted: 18 June 2019

Published online: 24 June 2019

\section{References}

1. Bhagavathi S, Fu K. Primary lymphoma of bone: a review. Semin Diagn Pathol. 2014;31:48-52.

2. Cheson BD, Fisher RI, Barrington SF, et al. Recommendations for initial evaluation, staging, and response assessment of Hodgkin and non-Hodgkin lymphoma: the Lugano classification. J Clin Oncol. 2014;32(27):3059-68.

3. Chen YH, Gong Y. Cytopathology in the diagnosis of lymphoma. Cancer Treat Res. 2014;160:211-40.

4. Küppers R, Dührsen U, Hansmann ML. Pathogenesis, diagnosis, and treatment of composite lymphomas. Lancet Oncol. 2014;15:e435-46.

5. Ansell SM. Non-Hodgkin lymphoma: diagnosis and treatment. Mayo Clin Proc. 2015:90:1152-63.

6. Lal H, Neyaz Z, Nath A, et al. CT-guided percutaneous biopsy of intrathoracic lesions. Korean J Radiol. 2012;13:210-26.

7. Zhang HF, Zeng XT, Xing F, et al. The diagnostic accuracy of CT-guided percutaneous core needle biopsy and fine needle aspiration in pulmonary lesions: a meta-analysis. Clin Radiol. 2016;71:e1-10

8. Metz T, Heider A, Vellody R, et al. Image-guided percutaneous core needle biopsy of soft-tissue masses in the pediatric population. Pediatr Radiol. 2016;46:1173-8.

9. Sainani $\mathrm{NI}$, Schlett $\mathrm{CL}$, Hahn PF, et al. Computed tomography-guided percutaneous biopsy of isoattenuating focal liver lesions. Abdom Imaging. 2014:39:633-44.

10. Rimondi E, Rossi G, Bartalena T, et al. Percutaneous CT-guided biopsy of the musculoskeletal system: results of 2027 cases. Eur J Radiol. 2011:77:34-42.

11. Wang Z, Li X, Chen J, et al. Value of computed tomography-guided core needle biopsy in diagnosis of primary pulmonary lymphomas. J Vasc Interv Radiol. 2013;24:97-102

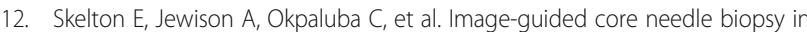
the diagnosis of malignant lymphoma. Eur J Surg Oncol. 2015:41:852-8.

13. Frederiksen JK, Sharma M, Casulo C, et al. Systematic review of the effectiveness of fine-needle aspiration and/or core needle biopsy for subclassifying lymphoma. Arch Pathol Lab Med. 2015;139:245-51.

14. Gaudio F, Pedote P, Ferrante A, et al. CT-guided needle biopsy performed with modified coaxial technique in patients with refractory or recurrent lymphomas. Ann Hematol. 2014:93:1559-64.

15. Balestreri L, Morassut S, Bernardi D, et al. Efficacy of CT-guided percutaneous needle biopsy in the diagnosis of malignant lymphoma at first presentation. Clin Imaging. 2005;29:123-7.

16. Nguyen BM, Halprin C, Olimpiadi Y, et al. Core needle biopsy is a safe and accurate initial diagnostic procedure for suspected lymphoma. Am J Surg. 2014;208:1003-8.

17. Omura MC, Motamedi K, UyBico S, et al. Revisiting CT-guided percutaneous core needle biopsy of musculoskeletal lesions: contributors to biopsy success. AJR Am J Roentgenol. 2011:197:457-61.

18. Yang J, Frassica FJ, Fayad L, et al. Analysis of nondiagnostic results after image-guided needle biopsies of musculoskeletal lesions. Clin Orthop Relat Res. 2010;468:3103-11.
19. Nouh MR, Abu Shady HM. Initial CT-guided needle biopsy of extremity skeletal lesions: diagnostic performance and experience of a tertiary musculoskeletal center. Eur J Radiol. 2014;83:360-5.

20. Didolkar MM, Anderson ME, Hochman MG, et al. Image guided core needle biopsy of musculoskeletal lesions: are nondiagnostic results clinically useful? Clin Orthop Relat Res. 2013:471:3601-9.

21. Li Y, Du Y, Luo TY, et al. Factors influencing diagnostic yield of CT-guided percutaneous core needle biopsy for bone lesions. Clin Radiol. 2014;69:e43-7.

22. Chang CY, Huang AJ, Bredella MA, et al. Percutaneous CT-guided needle biopsies of musculoskeletal tumors: a 5-year analysis of non-diagnostic biopsies. Skelet Radiol. 2015:44:1795-803.

23. Didolkar MM, Anderson ME, Hochman MG, et al. Image guided core needle biopsy ofmusculoskeletal lesions: are nondiagnostic results clinically useful? Clin Orthop Relat Res. 2013;471:3601-9.

24. Wu JS, Goldsmith JD, Horwich PJ, et al. Bone and soft-tissue lesions: what factors affect diagnostic yield of image-guided core-needle biopsy? Radiology. 2008;248:962-70.

25. Regacini R, Puchnick A, Shigueoka DC, et al. Whole-body diffusion-weighted magnetic resonance imaging versus FDG-PET/CT for initial lymphoma staging: systematic review on diagnostic test accuracy studies. Sao Paulo Med J. 2015;133:141-50.

26. Ansell SM, Armitage JO. Positron emission tomographic scans in lymphoma: convention and controversy. Mayo Clin Proc. 2012;87:571-80.

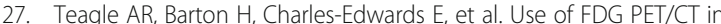
identification of bone marrow involvement in diffuse large B cell lymphoma and follicular lymphoma: comparison with iliac crest bone marrow biopsy. Acta Radiol. 2017;58:1476-84.

28. Sabattini E, Bacci F, Sagramoso C, Pileri SA. WHO classification of tumours of haematopoietic and lymphoid tissues in 2008: an overview. Pathologica. 2010;102:83-7.

29. Guo W, Hao B, Chen HJ, et al. PET/CT-guided percutaneous biopsy of FDGavid metastatic bone lesions in patients with advanced lung cancer: a safe and effective technique. Eur J Nucl Med Mol Imaging. 2017:44:25-32.

30. Bitencourt AG, Tyng CJ, Pinto PN, et al. Percutaneous biopsy based on PET/ $\mathrm{CT}$ findings in cancer patients: technique, indications, and results. Clin Nucl Med. 2012;37:e95-7.

31. Adams HJA, Kwee TC, de Keizer B, et al. FDG PET/CT for the detection of bone marrow involvement in diffuse large B cell lymphoma: systematic review and meta-analysis. Eur J Nucl Med Mol Imaging. 2014:41:565-74.

\section{Publisher's Note}

Springer Nature remains neutral with regard to jurisdictional claims in published maps and institutional affiliations.

Ready to submit your research? Choose BMC and benefit from:

- fast, convenient online submission

- thorough peer review by experienced researchers in your field

- rapid publication on acceptance

- support for research data, including large and complex data types

- gold Open Access which fosters wider collaboration and increased citations

- maximum visibility for your research: over $100 \mathrm{M}$ website views per year

At BMC, research is always in progress.

Learn more biomedcentral.com/submissions 